\title{
О НЕКОТОРЫХ ХИМИЧЕСКИХ РАВНОВЕСИЯХ В СИСТЕМЕ Cd-In-S
}

В [ $\left.{ }^{1}\right]$ исследованы химические равновесия и области твердых растворов на разрезе $\mathrm{In}_{2} \mathrm{~S}_{3}-\mathrm{CdS}$ тройной системы $\mathrm{Cd}-\mathrm{In}-\mathrm{S}$. В настоящей работе изучены разрезы In-CdS, In-CdIn $\mathrm{S}_{4}$ и $\mathrm{In}_{3} \mathrm{~S}_{4}-\mathrm{CdIn}_{2} \mathrm{~S}_{4}$ той же системы. Методика эксперимента не отличалась от описанной в работе [1 $]$.

\section{Экспериментальные данные}

На основе данных дифференциально-термического (ДТА) и фазового анализов построены диаграммы состояния исследованных разрезов.

1. Р а з рез In-CdS. Нндий плавится при $156,4^{\circ} \mathrm{C}$. Температура плавления сульфида кадмия по [2] $1475 \pm 15^{\circ}$ и по [3] $1370^{\circ}$. Нами проведен ДТА при семи разных соотношениях компонентов. На кривых нагревания исследованных сплавов индия и сульфида кадмия наблюдается по два термических эффекта, соответствующих температурам ликвидуса и солидуса. По данным ДТА построена фазовая диаграмма разреза In-CdS, приведенная на рис. 1. Температура ликвидуса повышается плавно от эвтектической горизонтали, лежащей при $155 \pm 3^{\circ}$, до температуры плавления сульфида кадмия. Ниже линии ликвидуса происходит первичная кристаллизация сульфида кадмия. Затвердевание всех сплавов заканчивается при эвтектической температуре. Малое отличие эвтектической температуры от температуры плавления индия свидетельствует о практически вырожденной эвтектике, на что указывает и ход кривой ликвидуса. Микроструктурный анализ показывает существование двух фаз у всех исследованных образцов. По характеру треугольника Таммана, построенного по величине эвтектических эффектов, можно предположить, что при $155^{\circ}$ твердые растворы на основе сульфида кадмия практически отсутствуют. Для проверки образования твердых растворов индия в сульфиде кадмия при более высоких температурах были изготовлены образцы с содержанием 1, 3, 5 и 10 мол. \% индия в сульфиде кадмия, которые подвергались отжигу в течение 100 ч при температуре $1100^{\circ}$ и после этого закалялись в воде. Все образцы оказались двухфазными. На основе этого можно предположить, что твердые растворы на основе сульфида кадмия практически отсутствуют и при высоких температурах.

Разрез In-CdS следует рассматривать как квазибинарный разрез тройной системы $\mathrm{Cd}-\mathrm{In}-\mathrm{S}$. 
2. $\mathrm{P}$ а з р е з $\mathrm{In}-\mathrm{CdIn}_{2} \mathrm{~S}_{4}$, По данным ['], тройное соединение $\mathrm{CdIn}_{2} \mathrm{~S}_{4}$ плавится при $1125^{\circ} \pm 5^{\circ}$. Фазовая диаграмма разреза $\mathrm{In}-\mathrm{CdIn}_{2} \mathrm{~S}_{4}$, построенная по данным ДТА одиннадцати сплавов с разным соотношением компонентов, приведена на рис. 2

На термограммах сплавов с содержанием от 1,4 до 23,8 мол. \% $\mathrm{Cd} \operatorname{In}_{2} \mathrm{~S}_{4}$ наблюдалось по два термических эффекта, а на термоғраммах сплавов, содержащих от 28,4 до 73,9 мол. \% $\mathrm{CdIn}_{2} \mathrm{~S}_{4}$ - по три. При более высоком содержании тройного соединения на термограмме нами не наблюдалось четких термических эффектов.

Кривая ликвидуса понижается от $1125^{\circ}$ для $\mathrm{CdIn}_{2} \mathrm{~S}_{4}$ до монотектической горизонтали при $680 \pm 5^{\circ}$ и достигает последнюю при содержании $\mathrm{CdIn}_{2} \mathrm{~S}_{4}$ приблизительно 29 мол. \%. Ниже линии ликвидуса в этой области концентраций происходит первичная кристаллизация твердого раствора на основе $\mathrm{CdIn} \mathrm{S}_{4}$. В интервале концентраций приблизительно от 1 до 29 мол. \% $\mathrm{CdIn}_{2} \mathrm{~S}_{4}$ наблюдается расслаивание. Следует отметить, что оно наблюдается и в соответствующей части краевой диаграммы In-S [ [ ]. Можно предположить, что при содержании $\mathrm{CdIn}_{2} \mathrm{~S}_{4}$ меньше 1 мол. \%, кривая ликвидуса понижается от $680^{\circ}$ до әвтектической температуры при $155 \pm 3^{\circ}$. Система $\mathrm{In}-\mathrm{CdIn}_{2} \mathrm{~S}_{4}$, как и система In-CdS, очевидно, имеет вырожденную эвтектику.

Для исследования растворимости индия в твердом $\mathrm{CdIn}_{2} \mathrm{~S}_{4}$ образцы с содержанием 366 мол. \% индия в $\mathrm{CdIn}_{2} \mathrm{~S}_{4}$ отжигали при температуре, близкой к монотектической. Отжиг продолжался 100 ч, после чего образцы закалялись в воде. Образцы, содержащие индия менее 20 мол. \% при исследовании микроструктуры оказались однофазными. На основе этого можно предположить, что растворимость индия в твердом $\mathrm{CdIn}_{2} \mathrm{~S}_{4}$ при $680^{\circ}$ не менее 20 мол. \%. Сплавы с большим содержанием индия двухфазные.

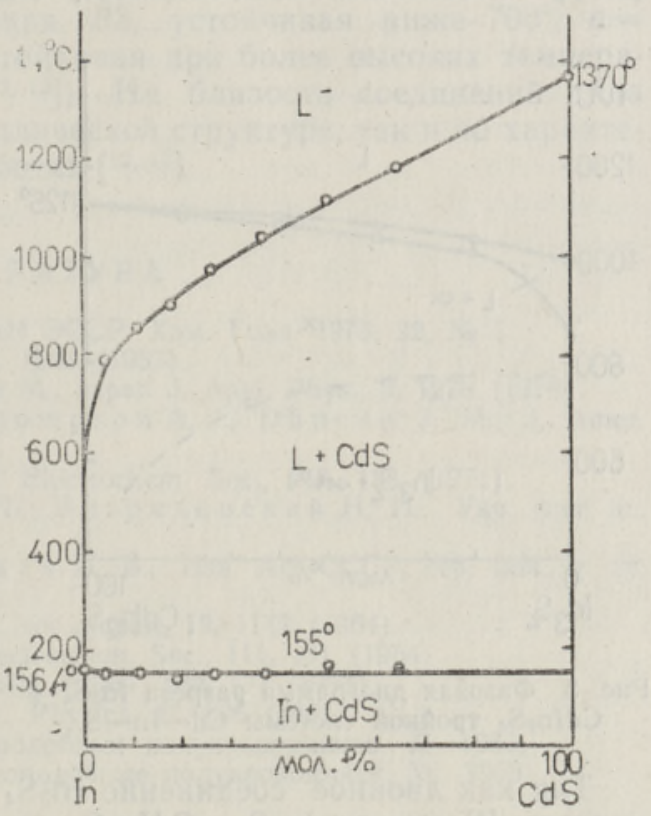

Рис. 1. Фазовая диаграмма разреза In-CdS тройнй системы Cd-In-S.

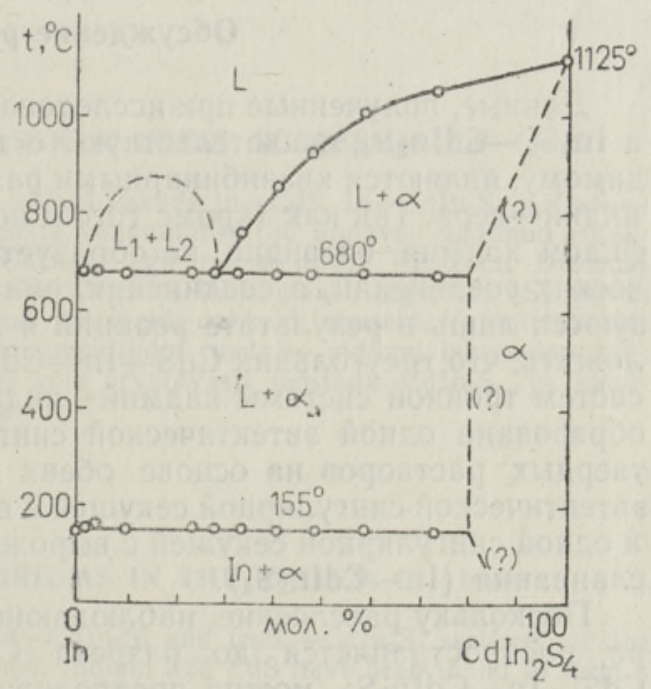

Рис. 2. Фазовая диаграмма разреза In$\mathrm{CdIn} \mathrm{S}_{4}$ тройной снстемы Cd-In-S.

Разрез In-CdIn $\mathrm{S}_{4}$ следует рассматривать как квазибинарный разрез тройной системы $\mathrm{Cd}-\mathrm{In}-\mathrm{S}$. 
3. Р а з е $3 \mathrm{In}_{3} \mathrm{~S}_{4}-\mathrm{CdIn}_{2} \mathrm{~S}_{4}$. Нами исследованы 6 различных составов от $\mathrm{In}_{3} \mathrm{~S}_{4}$ до $\mathrm{CdIn} \mathrm{S}_{4}$. На рис. 3 приведена фазовая диаграмма разреза, построенная по данным ДТА. На термограммах сплавов этого разреза наблюдается один растянутый термический эффект в интервале температур от 1000 до $1125^{\circ}$, характер которого, а также отсутствие какихлибо других ясно выраженных

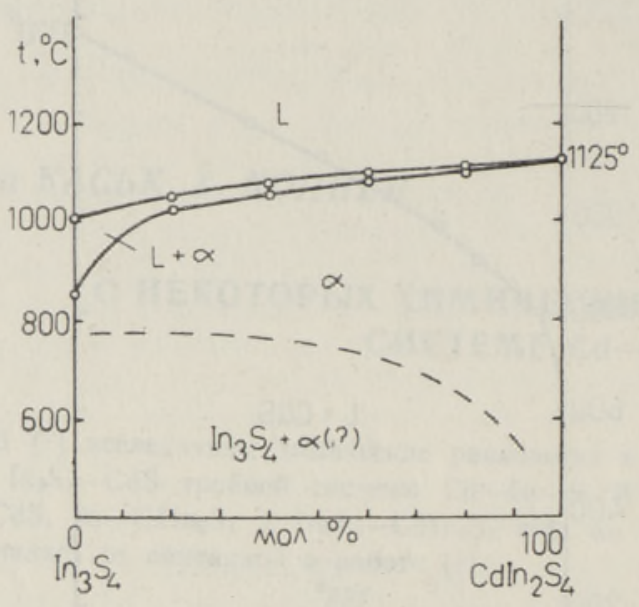

Рис. 3. Фазовая диаграмма разреза $\operatorname{In}_{3} \mathrm{~S}_{4}-$ $\mathrm{Cd} \mathrm{In}_{2} \mathrm{~S}_{4}$ тройной системы Cd-In-S. термических эффектов на термограммах данного разреза, очевидно, свидетельствует о том, что между $\mathrm{In}_{3} \mathrm{~S}_{4}$ и $\mathrm{CdIn}{ }_{2} \mathrm{~S}_{4}$ образуется непрерывный ряд твердых растворов, аналогично твердым растворам между $\operatorname{In}_{2} \mathrm{~S}_{3}$ и $\mathrm{CdIn}_{2} \mathrm{~S}_{4}$. Температуры ликвидуса и солидуса определялись по началу и концу этого эффекта как по кривым нагревания, так и по кривым охлаждения. В интервале температур от 600 до $800^{\circ}$ на термограммах наблюдается очень слабый эффект, который, по-видимому, может быть связан с распадом твердых растворов. Температура этого эффекта понижается с увеличением содержания $\mathrm{CdIn}_{2} \mathrm{~S}_{4}$ в сплавах.

Так как двойное соединение $\mathrm{In}_{3} \mathrm{~S}_{4}$ образуется при перитектической реакции [ $\left.{ }^{4}\right]$, разрез $\mathrm{In}_{3} \mathrm{~S}_{4}-\mathrm{CdIn} \mathrm{S}_{4}$ не является квазибинарным разрезом системы Cd-In-S. Позднее [5] существование соединения $\mathrm{In}_{3} \mathrm{~S}_{4}$ вообще ставится под серьезное сомнение.

\section{Обсуждение результатов}

Данные, полученные при исследовании разрезов In-CdS, In-CdIn $\mathrm{S}_{4}{ }^{*}$ и $\mathrm{In}_{3} \mathrm{~S}_{4}-\mathrm{CdIn} \mathrm{S}_{4}$, свидетельствуют о том, что первые два из них, по-видимому, являются квазибинарными разрезами тройной системы кадмийиндий-сера. Так как (кроме того и по данным[1]) между $\mathrm{CdIn}_{2} \mathrm{~S}_{4}$ и сульфидом кадмия, очевидно, не образуется плавящихся конгруентно химических соединений, а соединения, обнаруженные на этом разрезе, образуются лишь в результате реакций в твердом состоянии, можно предпо-

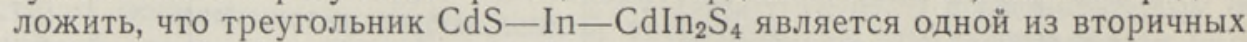
систем тройной системы кадмий-индий-сера. Эта вторичная система образована одной эвтектической сингулярной секущей с образованием твердых растворов на основе обеих компонент $\left(\mathrm{CdS}-\mathrm{Cd} \operatorname{In}_{2} \mathrm{~S}_{4}\right)$, одной эвтектической сингулярной секущей с вырожденной эвтектикой (In-CdS) и одной сингулярной секущей с вырожденной эвтектикой и областью расслаивания (In-CdIn $\left.\mathrm{S}_{4}\right)$.

Поскольку расслоение, наблюдающееся в двойной системе индий-сеpa, распространяется до разреза $\mathrm{Cd}-\mathrm{CdIn}_{2} \mathrm{~S}_{4}$ и вторичной системы $\mathrm{CdS}-\mathrm{In}-\mathrm{CdIn} \mathrm{S}_{4}$, можно предположить, что область расслоения пересекает весь треугольник $\mathrm{CdIn} \mathrm{I}_{4}-\mathrm{Cd}-\mathrm{In}_{2} \mathrm{~S}_{3}$.

Растворимость индия в твердом сульфиде кадмия сравнительно мала. По данным $\left[{ }^{6,7}\right]$, получен сульфид кадмия с содержанием индия около $10^{-2}$ мол. \%. Такой величине растворимости на разрезе индий-сульфид кадмия соответствуют и наши менее точные результаты. Зато на- 
блюдается в твердом сульфиде кадмия значительная растворимость индия в виде тройного соединения $\mathrm{CdIn}_{2} \mathrm{~S}_{4}$ (около 15 мол. \%) [1]. Такая аномально высокая растворимость примесного элемента только на одном разрезе в данном случае, по-видимому, может быть связана с тем, что кристаллическая структура $\mathrm{CdIn}_{2} \mathrm{~S}_{4}$ (кубическая $C^{\mathrm{V}}, a \approx 10,8 A\left[{ }^{8-11}\right]$ ) близка к структуре CdS (кубическая B3, устойчивая ниже $700^{\circ}, a=$ $=5,832 \AA$ и гексагональная $B 4$, устойчивая при более высоких температурах, $a=4,1348 \AA$ и $c=6,749 \AA[12,13])$. На близость соединений типа $A^{\mathrm{II}} B_{2}{ }^{\mathrm{III}} C_{4}$ VI ${ }^{\text {V }} A^{\mathrm{II}} B^{\mathrm{VI}}$ как по кристаллической структуре, так и по характеру химической связи указано в работах $\left[{ }^{12,13}\right]$.

\section{ЛИТЕРАТУРА}

1. К а ськ Рита, Коппел Х., Изв. АН ЭССР, Хим. Геол, 1973, 22, № 1.

2. Ad d a mi a no A., J. phys. chem., 61, 1253 (1957).

3. N a rit a K., W a t a n a be H., W a d a M., Japan J. Appl. Phys., 9, 1278 (1970)

4. Stubbs M. F., Schuffle J. A., Thompson A. J., Duncan J. M., J. Amer. Chem. Soc., 74, 1441 (1952).

5. Ansel H. G., B oorman R. S., J. Electrochem. Soc., 118, 133 (1971)

6. Курик М. В., Гавалешко М. П., Витриховский Н. И., Укр. физ.ж., т. IX, 1217 (1964).

7. Витриховский Н. И., Мизецкая И. Б., Изв. АН СССР, сер. физ,, т. 28, № $8,1316(1964)$.

8. Sh i on oy a S., T a m ot o Y., J. Phys. soc. Japan, 19, 1142 (1964).

9. Suchow L., S temple N. R., J. Electrochem. Soc., 111, 191 (1964).

10. $\mathrm{H}$ a hn H., Kling le r W., Z. anorg. allg. Chem., 263, 177 (1950).

11. Koelman s H., Grimme is s H. G., Physica, 27, 606 (1961).

12. Гор юнов а Н. А., Химия алмазоподобных полупроводников. Л. 1963.

13. Го рюн ов а Н. А., Сложные алмазоподобные полупроводники. М. 1968.
Ннститут физики
Академии наук Эстонской ССР
Поступила в редакцию 26/III 1973

Rita KASK, H. KOPPEL

\section{MONINGATEST KEEMILISTEST TASAKAALUDEST SOSTEEMIS $\mathrm{Cd}-\mathbf{I n}-\mathrm{S}$}

Koostati süsteemi kaadmium-indium-väävel lõikude In-CdS, In-CdIn $\mathrm{S}_{4}$ ja $\operatorname{In}_{3} \mathrm{~S}_{4}-$ $\mathrm{CdIn}_{2} \mathrm{~S}_{4}$ faasidiagrammid. Ilmnes, et indium ja kaadmiumsulfiid annavad kõdunud eutektikaga süsteemi, indium ja kolmikühend $\mathrm{CdIn}_{2} \mathrm{~S}_{4}$ aga moodustavad süsteemi kõdunud eutektikaga, indiumi lähedal asuva kihistumise alaga ja tahkete lahustega $\mathrm{CdIn}_{2} \mathrm{~S}_{4}$ alusel. Koostise In : $\mathrm{S}=3: 4 \mathrm{ja} \mathrm{CdIn}_{2} \mathrm{~S}_{4}$ vahel esineb pidev rida tahkeid lahuseid. Varem täheldatud $\mathrm{CdIn}_{2} \mathrm{~S}_{4}$ suurt lahustuvust tahkes kaadmiumsulfiidis (metalse indiumi lahustuvus tahkes kaadmiumsulfiidis on samal ajal väike) vōib arvatavasti seostada $\mathrm{CdIn}_{2} \mathrm{~S}_{4}$ ja kaadmiumsulfiidi kristallstruktuuride lähedusega.

Rita KASK, H. KOPPEL

\section{ON SOME CHEMICAL EQUILIBRIUMS IN THE SYSTEM $\mathrm{Cd}-\mathrm{In}-\mathrm{S}$}

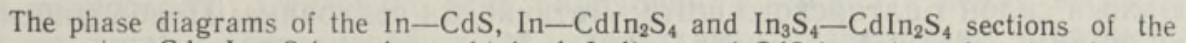
ternary system $\mathrm{Cd}-\mathrm{In}-\mathrm{S}$ have been obtained. Indium and $\mathrm{CdS}$ have been found to form a degenerated eutectic system. Indium and ternary compound $\mathrm{Cd} \mathrm{In}_{2} \mathrm{~S}_{4}$ have been found to form a system consisting of a degenerated eutectic, a region of delamination on the side of In and solid solutions on the basis of $\mathrm{CdIn}_{2} \mathrm{~S}_{4}$. A continuous series of solid solutions between the composition In : S=3:4 and $\mathrm{CdIn}_{2} \mathrm{~S}_{4}$ has been observed. Previously observed high solubility of $\mathrm{CdIn}_{2} \mathrm{~S}_{4}$ in solid CdS, while the solubility of metal In in solid CdS is low, should presumably be associated with some similarity of the crystal structures of $\mathrm{CdIn}_{2} \mathrm{~S}_{4}$ and CdS. 